\title{
HELLP syndrome: An experience of treating with plasma exchange
}

\author{
Shahzadi Sayeeda Tun Nessa, ${ }^{1}$ Mohammd Mufizul Islam Polash, ${ }^{2}$ Md. Motiul Islam, ${ }^{3}$ Ahmad Mursel Anam, ${ }^{4}$
}

Muhammad Mahbubur Rahman Bhuiyan ${ }^{5}$

\begin{abstract}
:
In the spectrum of patient with severe pre-eclampsia, there is a potentially lethal complication called HELLP syndrome( haemolysis, elevated liver enzyme and low platelet count). I The pathogenesis of HELLP syndrome is unclear. If it is a form of severe preeclampsia, it likely originates from aberrant placental development and function. As an independent entity, it has been attributed to abnormal placentation, similar to preeclampsia, but with greater hepatic inflammation and greater activation of the coagulation system than in preeclampsia.2,3,4 HELLP develops in approximately 0.5 to 0.9 percent of all pregnancies and in 10 to 20 percent of women with severe preeclampsialeclampsia. ${ }^{5}$ Maternal mortality rate in HELLP syndrome is variable (1-23\%) due to severity of disease, delayed diagnosis and presence of multi-organ involvement. ${ }^{6,7}$ So the recognition of HELLP syndrome and an aggressive multidisciplinary approach are required for the improvement of meternofoetal prognosis.
\end{abstract}

Key Words: HELLP, Preeclampsia, Therapeutic Plasma Exchange.

\section{Introduction:}

HELLP syndrome and severe preeclampsia are probably part of the same disease spectrum. A precise definition of HELLP is necessary for research purposes and for predicting maternal complications as well as for deciding treatment modality.

As per Tennessee Criteria, we require the presence of all of the following to diagnose HELLP: 9

- Microangiopathic hemolytic anemia with characteristic schistocytes (also called helmet cells) on blood smear. Other signs suggestive of hemolysis include an elevated LDH or indirect bilirubin and a low serum haptoglobin concentration $(\leq 25 \mathrm{mg} / \mathrm{dL})$.

- Platelet count $\leq 100,000$ cells $/ \mathrm{microL}$

- Serum $\mathrm{LDH} \geq 600 \mathrm{IU} / \mathrm{L}$ or total bilirubin $\geq 1.2 \mathrm{mg} / \mathrm{dL}$

- Serum AST $\geq 70 \mathrm{IU} / \mathrm{L}$. Some investigators obtain ALT levels instead of, or in addition to, AST levels. An advantage of the AST is that it is a single test that reflects both hepatocellular necrosis and red cell hemolysis. ${ }^{9}$

1. Shahzadi Sayeeda Tun Nessa MBBS, Clinical Staff, Intensive Care Unit

2. Mohammd Mufizul Islam Polash, MBBS, Clinical Staff, Intensive Care Unit

3. Md. Motiul Islam MBBS, Clinical Staff, Intensive Care Unit

4. Ahmad Mursel Anam, MBBS, Chief Resident, Intensive Care Unit

5. Dr. Muhammad Mahbubur Rahman Bhuiyan, MBBS, Clinical Staff, Intensive Care Unit

All the authors work in SQUARE Hospital Limited, 18/F, BU Qazi Nuruzzaman Sarak (West Panthapath), Dhaka 1205, Bangladesh.

Corresponding Author:

Dr. Shahzadi Sayeeda Tun Nessa MBBS, Clinical Staff, Intensive Care Unit, SQAURE Hospital, Dhaka

18/F, BU Qazi Nuruzzaman Sarak (West Panthapath), Dhaka 1205,
A less established criteria known as Mississippi Criteria; for prognostication of patient also exists which divides the patients into three groups based on lowest observed perinatal platelet count. Class 1 platelet nadir $<50,000 / \mathrm{cmm}$, Class $2>50,000-100,000 / \mathrm{cmm}$ and Class $3>100,000-$ $150,000 / \mathrm{cmm}$. This criteria along with multiorgan involvement may serve as a deciding factor for initiating plasma exchange.

Here we report a case diagnose to have HELLP syndrome and its successful management with plasma exchange.

\section{Case report:}

A 32 years, young women at her 38 weeks of gestation was admitted to ICU, SHL with epigastric pain, blood pressure $160 / 120 \mathrm{~mm}$ of $\mathrm{Hg}$ and proteinuria. She underwent emergency LSCS at the same day due to severe preeclamsia and foetal distress.

After surgery, she was conscious and alert without any neurological deficit. Her blood pressure remained elevated up to $160 / 120 \mathrm{~mm}$ of hg and required $\mathrm{i} / \mathrm{v}$ antihypertensive. She was maintaining $\mathrm{SPO}_{2} 94 \%$ with $41 \mathrm{t} / \mathrm{min} \mathrm{O}_{2}$. Abdomen was distended and diffusely tender. There is bleeding from venepuncture sites. Her initial blood counts in post operative period was within normal range. On 2 nd post operative period she developed severe thrombocytopenia (platelet 22X103/cmm with hemoglobin of $9.8 \mathrm{gm} / \mathrm{dl}$ and white blood count $22 \times 103 / \mathrm{cmm}$. Her coagulation profile was normal. Peripheral smear showed significant numbers of schistocytes suggestive of microangoiopathic hemolytic anemia(MAHA). Elevated ALT of 1104 IU and LDH of $12695 \mathrm{U}$ supported the diagnosis of MAHA. Culture of urine, sputum and blood that were sent for septic screening before starting antibiotic, turned out to be negative later on. Hepatitis viral markers (HAV, HBV, HCV \& HEV) were found negative also. Transabdominal USG revealed mild intraabdominal collection, with no organ injury. To rule out 
autoimmune disorder, antinuclear antibody, antineutophilic cytoplasmic antibodies were tested and found to be negative.

Her clinical and biochemical condition detoriated in 3rd post operative day. Patient became disoriented and urine output decreased to $100 \mathrm{ml}$ in 24 hours. Repeat hematological investigation revealed persistent thrombocytopenia and $\mathrm{Hb}$ dropped to $7 \mathrm{gm} / \mathrm{dl}$ and LDH level increased to $13,500 \mathrm{U}$. Her creatinine was also rising. A provisional diagnosis of post partum acute renal failure due to HELLP syndrome was made.

Hence, in view of the clinical deterioration an emergency therapeutic plasma exchange (TPE) was carried out after 48 hours of presentation. Four session of plasma exchange was done on a daily basis. As she became anuric \& renal function deteriorated hemodilysis was initiated. Supportive treatment with PRBC transfusion was also given when deemed necessary.
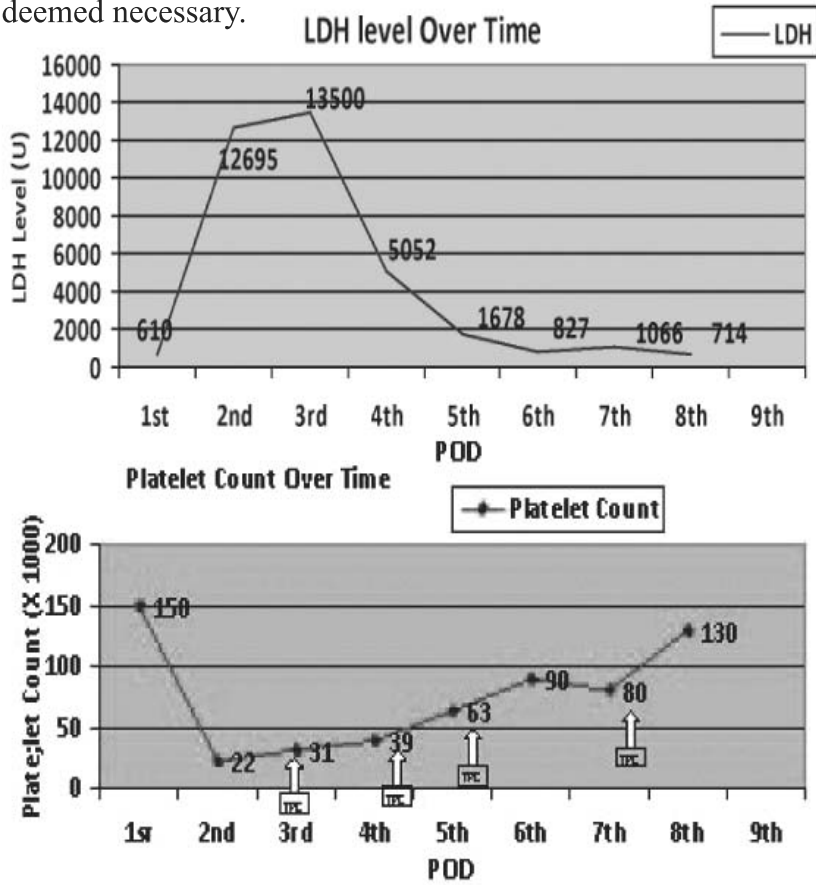

After 4 days of TPE, clinical and biochemical condition was improved and she was shifted from ICU to regular ward. She started having urine output after 7 days and that gradually increased and HD could be stopped at day 10 of presentation. She was discharged from hospital at 15 days of her hospital course with near normal renal function and without any evidence of ongoing hemolysis and normal platelet count.

\section{Discussion:}

Many aspect of HELLP syndrome are still controversial, such as diagnosis, classification and management. 10,11 During the post partum period, the majority of cases will show resolution of the disease within 72 hours of delivery; however, some patient, especially those with the persistent form of the disease, will not improve or will even get worse.
Some authors have suggested that such cases might get benefit from plasma exchange. 12 The exact mechanism of the effect of plasma exchange in HELLP syndrome is not known, but in general, plasma exchange removes plasma along with inflammatory marker and autoantibodies from patient and substitutes new elements from donor plasma.

There is thin line of demarcation which differentiates HELLP syndrome from other thrombocytopenia associated multiple organ failure like TTP/HUS. In this case, patient was diagnosed as a case of HELLP syndrome. As patient's clinical and biochemical condition was deteriorating in post partum period and diagnosed as class-I HELLP syndrome and had developed multiorgan failure, TPE was initiated and patient improved rapidly and her renal recovery took also significantly less time.

Although large scale controlled trials are not available till date and further study is needed; Therapeutic Plasma Exchange could be an option in patients refractory to standard management or who have Class I HELLP or develops multiorgan failure.

\section{References:}

1. Weinstein L, Syndrome of hemolysis, elevated liver enzyme, and low platelet count: a severe consequence of hypertension in pregnancy. Am J Obstet Gynecol 1982;142 :159-67

2. Abildgaard U, Heimdal K. Pathogenesis of the syndrome of hemolysis, elevated liver enzymes, and low platelet count (HELLP): a review. Eur J Obstet Gynecol Reprod Biol 2013; 166:117.

3. Benedetto C, Marozio L, Tancredi A, et al. Biochemistry of HELLP syndrome. Adv Clin Chem 2011; 53:85.

4.Jebbink J, Wolters A, Fernando F, et al. Molecular genetics of preeclampsia and HELLP syndrome - a review. Biochim Biophys Acta 2012; 1822:1960.

5. Haram K, Svendsen E, Abildgaard U. The HELLP Syndrome : Clinical Issues and Management. A Review. BMC Pregnancy Childbirth 2009; 9:8.

6. Martin JN Jr, Perry KG, Miles JF Jr,,et al. The interrelationship of Eclampsia, HELLP Syndrome and Prematurity : Cofactor for significant maternal and perinatal risk. Br J Obstet Gynecol 1993; 100: $1695-100$.

7. Sibai BM, Ramadan MK, Usta, et al. Maternal mortality and morbidity in 442 pregnancies with haemolysis, elevated liver enzyme, and low platelets (HELLP syndrome).Am J Obstet Gynecol 1993;169:1000-6

8.Sibai BM, Ramadan MK, Usta I, et al. Maternal morbidity and mortality in 442 pregnancies with hemolysis, elevated liver enzymes, and low platelets (HELLP syndrome). Am J Obstet Gynecol 1993; 169:1000.

9. Martin JN Jr, Blake PG, Lowry SL, et al. Pregnancy Complicated by Preeclampsia - eclampsia with the syndrome of hemolysis, elevated liver enzyme and low platelet count: how rapid is postpartum recovery?. Obstet Gynecol 1990; 76:737-41.

10. O'Brien JM, Barton JR. Controversies with the diagnosis and management of HELLP syndrome. Clin Obstet Gynecol 2005;48 $: 460-77$

11.Sibai BM . diagnosis, controversies, and management of the syndrome of hemolysis, elevated liver enzymes and low platelet count.Obstet Gynecol 2004; 103: 981 -91

12. Martin JN Jr, Files JC, Blake PG , et al. Postpartum plasma exchange for atypical preeclmsia-eclampsia as HELLP (hemolysis, elevated liver enzyme, and low platelet count) syndrome. Am J 